\title{
Effects of Idebenone (CV-2619) on Endogenous Monoamine Release and Cyclic AMP Formation in Diencephalon Slices from Rats
}

\author{
Shigehiko NARUMI, Akinobu NAGAOKA and Yuji NAGAWA \\ Central Research Division. Takeda Chemical Industries, Ltd. \\ Juso-Honmachi, Yodogawa-ku, Osaka 532, Japan
}

Accepted December 10, 1984

\begin{abstract}
The addition of $\mathrm{CV}-2619\left(10^{-4} \mathrm{M}\right)$ stimulated the release of endogenous 5 -hydroxytryptamine (5-HT) markedly and that of norepinephrine (NE) slightly from slices of rat diencephalon, but it did not affect dopamine (DA) release. The addition of $\mathrm{CV}-2619\left(10^{-5}-10^{-4} \mathrm{M}\right)$ or $5-\mathrm{HT}\left(10^{-6}-10^{-4} \mathrm{M}\right)$ stimulated cyclic AMP formation in a concentration-dependent manner. Methysergide $\left(10^{-4} \mathrm{M}\right)$, a $5-\mathrm{HT}$ receptor blocker, almost completely blocked CV-2619 $\left(10^{-4} \mathrm{M}\right)$ - and 5 - HT $\left(10^{-4}\right.$ $\mathrm{M})$-induced cyclic AMP formation. These results suggest that CV-2619 stimulates cyclic AMP formation via endogenous monoamine, particularly, 5-HT release.
\end{abstract}

A novel quinonyl compound, 6-(10hydroxydecyl)-2,3-dimethoxy-5-methyl-1.4benzoquinone (idebenone, $\mathrm{CV}$-2619) is being developed as a drug that improves brain metabolism. It has unique pharmacological actions such as a protective action against the spontaneous occurrence of stroke and cerebral ischemia induced-stroke in spontaneously hypertensive rats, and it has an ameliorating effect on learning and memory disturbances induced by cerebral ischemia in rats $(1,2)$. We already reported that $\mathrm{CV}$ 2619 enhances 5-HT turnover in the hippocampus, diencephalon and brain stem of rats (3). In the present report, we provide further evidence that CV-2619 stimulates endogenous 5 -HT release and cyclic AMP formation in slices of rat diencephalon.

Male Wistar rats (9-12 weeks old) were used for all experiments. The following drugs and analytical grade of reagents were used: $\mathrm{CV}-2619$ (idebenone), pargyline $\mathrm{HCl}$ (Nakarai Chemical), 5-hydroxytryptamine creatinine sulfate complex $(5-H T)$, Lnorepinephrine $\mathrm{HCl}$ (NE), DL-propranolol $\mathrm{HCl}$ (Sigma), methysergide hydrogen maleate (Sandoz), theophylline $\mathrm{HCl}$ (Tokyo Kasei), cyclic AMP assay kit (Yamasa Shoyu).

Rat diencephalon (thalamus+hypothalamus) was sliced to a thickness of $0.5 \mathrm{~mm}$ with a Mcllwain tissue chopper. Slices of $200 \mathrm{mg}$ wet weight in a teflon gauze holder were immersed into $1 \mathrm{ml}$ of $95 \% \mathrm{O}_{2}-5 \% \mathrm{CO}_{2}$ saturated Krebs-Ringer phosphate buffer (KRPB) containing $0.1 \mathrm{mM}$ pargyline and 10 $\mathrm{mM}$ glucose prewarmed at $37^{\circ} \mathrm{C}$, and transferred to different tubes containing the same buffer every $5 \mathrm{~min}$ for $60 \mathrm{~min}$. CV-2619 dissolved in $1 \%$ ethanol and other agents dissolved in KRPB or their vehicle were applied from 30 to $45 \mathrm{~min}$ after the start of the experiment. The monoamine levels in the incubation media collected every $5 \mathrm{~min}$ for $60 \mathrm{~min}$ and in the supernatant $(3,000 \mathrm{~g}$ for $10 \mathrm{~min}$ at $4^{\circ} \mathrm{C}$ ) of homogenized slices in $0.05 \mathrm{M}$ perchloric acid were measured by means of high performance liquid chromatography with electrochemical detection (3). Cyclic AMP accumulation (without theophylline) or formation (with theophylline) in the diencephalon slices was determined by radioimmunoassay using a Yamasa cyclic AMP assay kit (4).

Statistical comparison between different treatments was made using Student's $t$-test (two-tailed).

As shown in Fig. 1, the addition of $\mathrm{CV}$ $2619\left(10^{-4} \mathrm{M}\right)$ stimulated endogenous $5-\mathrm{HT}$ release markedly and NE release slightly, but not DA release from the diencephalon slices. 

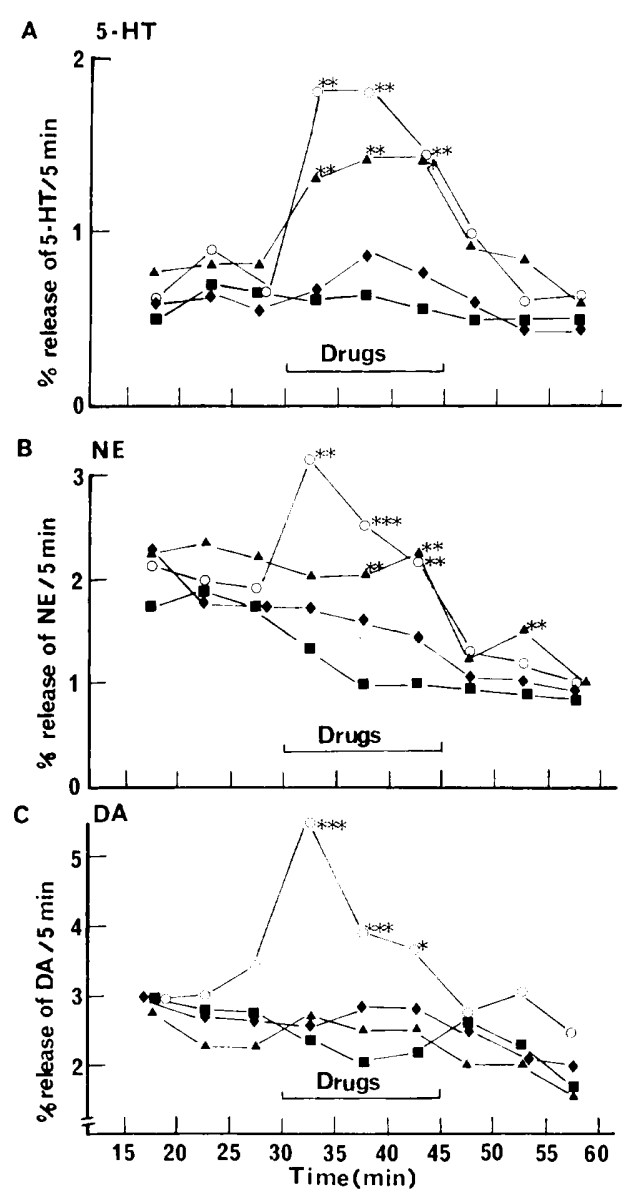

Fig. 1. Effects of CV-2619 on the release of endogenous 5-hydroxytryptamine (5-HT), norepinephrine (NE) and dopamine (DA) from rat diencephalon slices. All values are the mean of $5-6$ determinations. ${ }^{*} \mathrm{P}<0.05,{ }^{*} \mathrm{P}<0.01,{ }^{*}{ }^{*} \mathrm{P}<0.001$ vs. each control group. Control ( $1 \%$ ethanol), $\mathrm{O}: 5 \times 10^{-2} \mathrm{M} \mathrm{KCl}, \boldsymbol{\Delta}: 10^{-4} \mathrm{M} \mathrm{CV}-2619, \bullet: 3 \times 10^{-5}$ $\mathrm{MCV}-2619$.

$\%$ release of monoamines $=\frac{\text { Monoamine levels in } 5 \text { - }}{\text { Total monoamine levels }}$ min incubation medium

(slices+all incubation media) $\times 100$

A lower concentration $\left(3 \times 10^{-5} \mathrm{M}\right)$ of $\mathrm{CV}$ 2619 had little effect on the endogenous monoamine release. In contrast, $\mathrm{KCl}\left(5 \times 10^{-2}\right.$ $\mathrm{M})$ non-selectively stimulated the release of 5-HT, NE and DA to a similar degree (Fig. 1).

The addition of CV-2619 $\left(3 \times 10^{-5}\right.$ and $\left.10^{-4} \mathrm{M}\right)$ did not affect cyclic AMP accumulation in the diencephalon slices in the absence of theophylline, a phosphodiestrase inhibitor. Theophylline $\left(10^{-3}\right.$ and $\left.10^{-2} \mathrm{M}\right)$ accelerated cyclic AMP accumulation in a concentration-dependent manner.

As shown in Table 1, the addition of $\mathrm{CV}$. $2619\left(10^{-5}, 3 \times 10^{-5}\right.$ and $\left.10^{-4} \mathrm{M}\right)$ accelerated cyclic AMP formation in the diencephalon slices in the presence of theophylline $\left(10^{-2} \mathrm{M}\right)$ in a concentration-dependent manner. Both 5-HT $\left(10^{-6}-10^{-4} \mathrm{M}\right)$ and NE $\left(10^{-7}-10^{-5} \mathrm{M}\right)$ markedly stimulated cyclic AMP formation in the same experiment. Methysergide $\left(10^{-4} \mathrm{M}\right)$, a $5-\mathrm{HT}$ receptor blocker, almost compeltely blocked CV-2619 $\left(10^{-4} \mathrm{M}\right)$ - and 5 - HT $\left(10^{-4} \mathrm{M}\right)$-induced cyclic AMP formation. Propranolol $\left(10^{-4} \mathrm{M}\right)$, an adrenergic $\beta$-receptor blocker, had no effect on the CV-2619-induced effect, but almost completely blocked NE $\left(10^{-5} \mathrm{M}\right)$-induced cyclic AMP formation.

We already reported that CV-2619 at a dose of $100 \mathrm{mg} / \mathrm{kg}$ (i.p.) in normal rats and at $10 \mathrm{mg} / \mathrm{kg}$ (i.p.) in rats with cerebral ischemia markedly increased the main metabolite of 5-HT, 5-hydroxyindole-3acetic acid (5-HIAA), in the hippocampus, diencephalon and brain stem, but did not affect the monoamine contents (3). CV-2619 (30 and $100 \mathrm{mg} / \mathrm{kg}$, i.p.) also accelerated $\mathrm{p}$ chlorophenylalanine (PCPA)-induced 5-HT decreases in these brain regions of normal rats. The addition of CV-2619 $\left(3 \times 10^{-5}\right.$ and $\left.10^{-4} \mathrm{M}\right)$ to the superfusion media markedly increased the prelabelled $\left[{ }^{14} \mathrm{C}\right]-5-\mathrm{HT}$ release, and it slightly inhibited $\left[{ }^{14} \mathrm{C}\right]-5-\mathrm{HT}$ uptake in the hippocampal slices (3).

In the present report, we provide conclusive evidence that $\mathrm{CV}-2619\left(10^{-4} \mathrm{M}\right)$ stimulates endogenous $5-\mathrm{HT}$ release markedly and NE release slightly, but not DA release from the diencephalon slices in rats, and it also increases cyclic AMP formation in the same slices. Methysergide, but not propranolol, almost completely blocked the CV-2619induced cyclic AMP formation. A lower concentration $\left(10^{-5} \mathrm{M}\right)$ of $\mathrm{CV}-2619$ increased cyclic AMP formation, but not 5 - HT release (data not shown). This discrepancy was due to the difference of sensitivity and accuracy of both experiments. These results suggest that CV-2619 increases cyclic AMP formation mainly via 5 - $H$ T release. 
Table 1. Effects of CV-2619,5-hydroxytryptamine (5-HT) and norepinephrine (NE) alone or in combination with methysergide or propranolol on cyclic AMP formation in rat diencephalon slices in the presence of $10 \mathrm{mM}$ theophylline

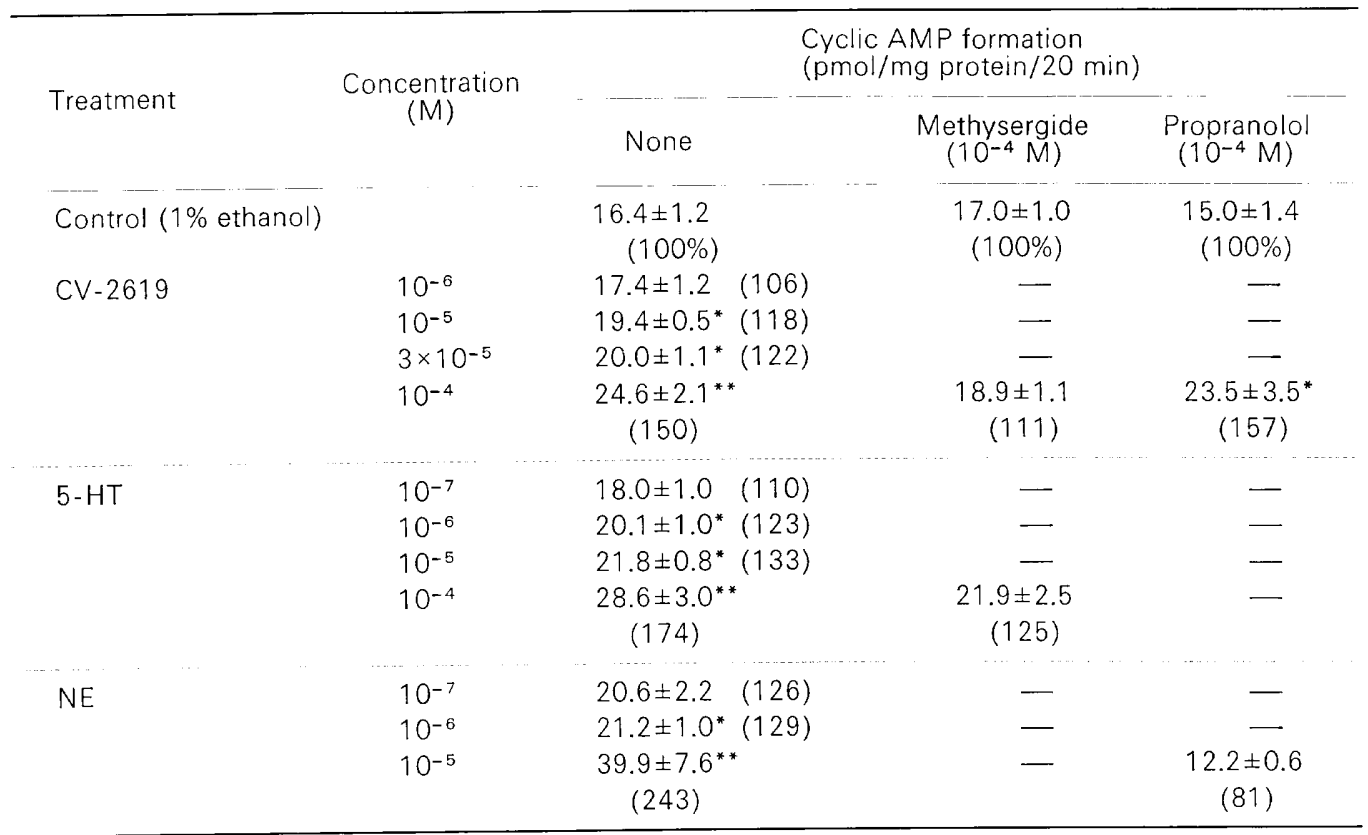

All values are the mean \pm S.E.M. of 10 determinations. ${ }^{*} \mathrm{P}<0.05,{ }^{*} \mathrm{P}<0.01 \mathrm{vs.} 1 \%$ ethanol control group. Slices and drugs were incubated at $37^{\circ} \mathrm{C}$ for 20 -min in Krebs-Ringer phosphate buffer containing $10 \mathrm{mM}$ theophylline.

Charney et al. indicated an important role of 5 - HT in mood regulation in healthy humans (5). In view of the ability of CV-2619 to stimulate endogenous 5 - HT release from rat brain slices, CV-2619 may elevate the feeling or improve the mood of patients with cerebrovascular disorders. CV-2619 improves passive avoidance in cerebral ischemiainduced learning and memory disturbances in rats (2). It has been hypothesized that cerebral cyclic AMP may act as the final common pathway of several classes of pharmacological agents that facilitate the memory process in animals $(6,7)$. Therefore, it is anticipated that CV-2619 may improve memory disturbances by increasing cerebral cyclic AMP formation via endogenous $5-\mathrm{HT}$ release.

Acknowledgments: The authors would like to thank Dr. J.R. Miller for his helpful comments on the manuscript and thank Miss C. Hattori for her technical assistance.

\section{References}

1 Nagaoka, A., Suno, M., Shibota, M. and Kakihana, M.: Effects of idebenone (CV-2619) on neurological deficits, local cerebral blood flow, and energy metabolism in rats with experimental cerebral ischemia. Folia Pharmacol. Japon. 84, 303-309 (1984) (Abs. in English).

2 Yamazaki, N., Take, Y., Nagaoka, A. and Nagawa, Y.: Beneficial effect of idebenone ( $C V-2619)$ on cerebral ishcemia-induced amnesia in rats. Japan. J. Pharmacol. 36, 349-356 (1984)

3 Narumi, S., Nagai, Y., Kakihana, M., Yamazaki, N., Nagaoka, A. and Nagawa, Y.: Effects of idebenone (CV-2619) on metabolism of monoamine, especially serotonin, in the brain of normal rats and rats with cerebral ischemia. Japan. J. Pharmacol. (1985) (in press)

4 Narumi, S., Nagai, Y., Saji, Y. and Nagawa, Y.: Increase in rat regional brain cyclic nucleotides by thyrotropin-releasing hormone (TRH) and its analog DN-1417. Japan. J. Pharmacol. 33, 915926 (1983)

5 Charney, D.S., Heninger, G.R., Reihard, J.F., Jr., Sternberg, D.E. and Hafstead, K.M.: The 
effect of intravenous L-tryptophan on prolactin and growth hormone and mood in healthy subjects. Psychopharmacology (Berlin) 77, 217222 (1982)

6 Chute, D.L., Villiger, J.W. and Kirton, N.F.: Testing cyclic AMP mediation of memory: Reversal of $\alpha$-methyl-P-tyrosine-induced amnesia. Psychopharmacolgy (Berlin) 74, 129131 (1981)

7 Randt, C.T., Judge, M.E., Bonnet, K.A. and Quartermain, D.: Brain cyclic AMP and memory in mice. Pharmacol. Biochem. Behav. 17, 677682 (1982) 